\title{
ON THE MORPHOLOGY OF THE OVIPOSITOR OF CERTAIN ANTHOMYIAN GENERA*
}

\author{
Hugh C. Huckett.
}

CONTENTS.

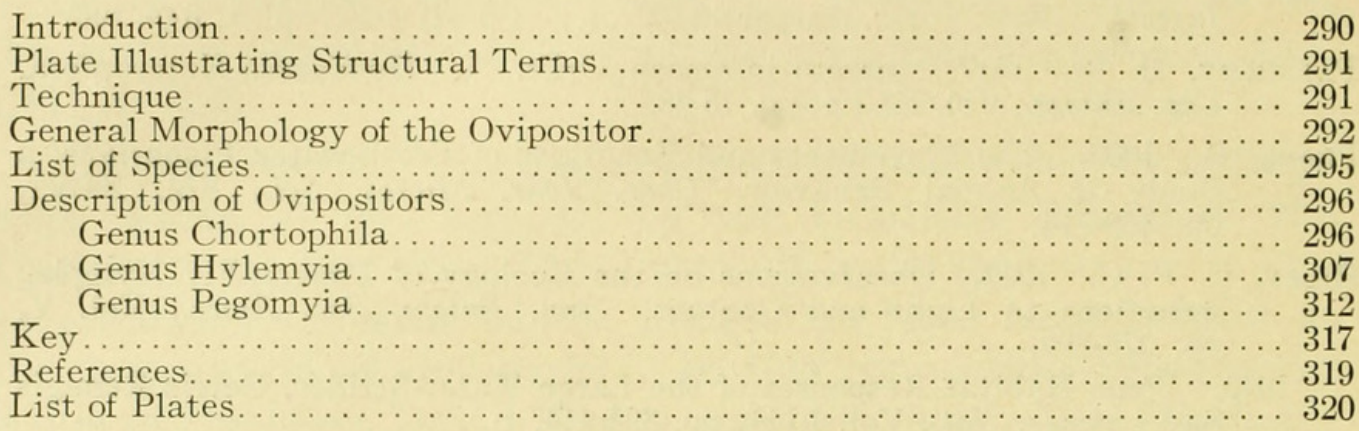

\section{INTRODUCTION.}

This difficult family of flies has caused not only the systematist but also the economic entomologist no little misapprehension due to the unsatisfactory conception of existing taxonomic characters. The generic definitions are also ambiguous and are at present undergoing a thorough revision. This is especially true of the three genera Chortophila Macquart, Hylemyia Desvoidy, and Pegomyia Desvoidy. The male species have been studied with a certain amount of detail and success, but the females have been neglected and owing to their peculiar characters are not capable of being classified according to male specimens. Stein (Archiv für Naturgeschichte 1914, viii: 4-55) has formulated a key for the determination of European female species and the paper has been largely used for the determination of the American species dealt with in the following pages.

The unsatisfactory nature, however, of such a position lead the writer to undertake the morphological study of the ovipositors of certain species of the above named genera in the hope that it would at least aid in determining without further doubt the identity of any female specimen.

The material for study was furnished by the Cornell University Collection, Dr. O. A. Johannsen's own collection and the author's specimens caught at Burlington, Ontario, and

* Since this paper was prepared for publication, Malloch has introduced a new concept of the genera mentioned herewith. 
around Ithaca. In the determination of specimens use has been made of Stein's keys to the females of European Anthomyidæ and the determined material in the above private collections.

The writer wishes to acknowledge the advice and help received from Dr. O. A. Johannsen in the determination of species and in the loan of the above collections without which the work would have been impossible.

\section{OVIPOSITOR (hypothetical) lllustrating structural terms}

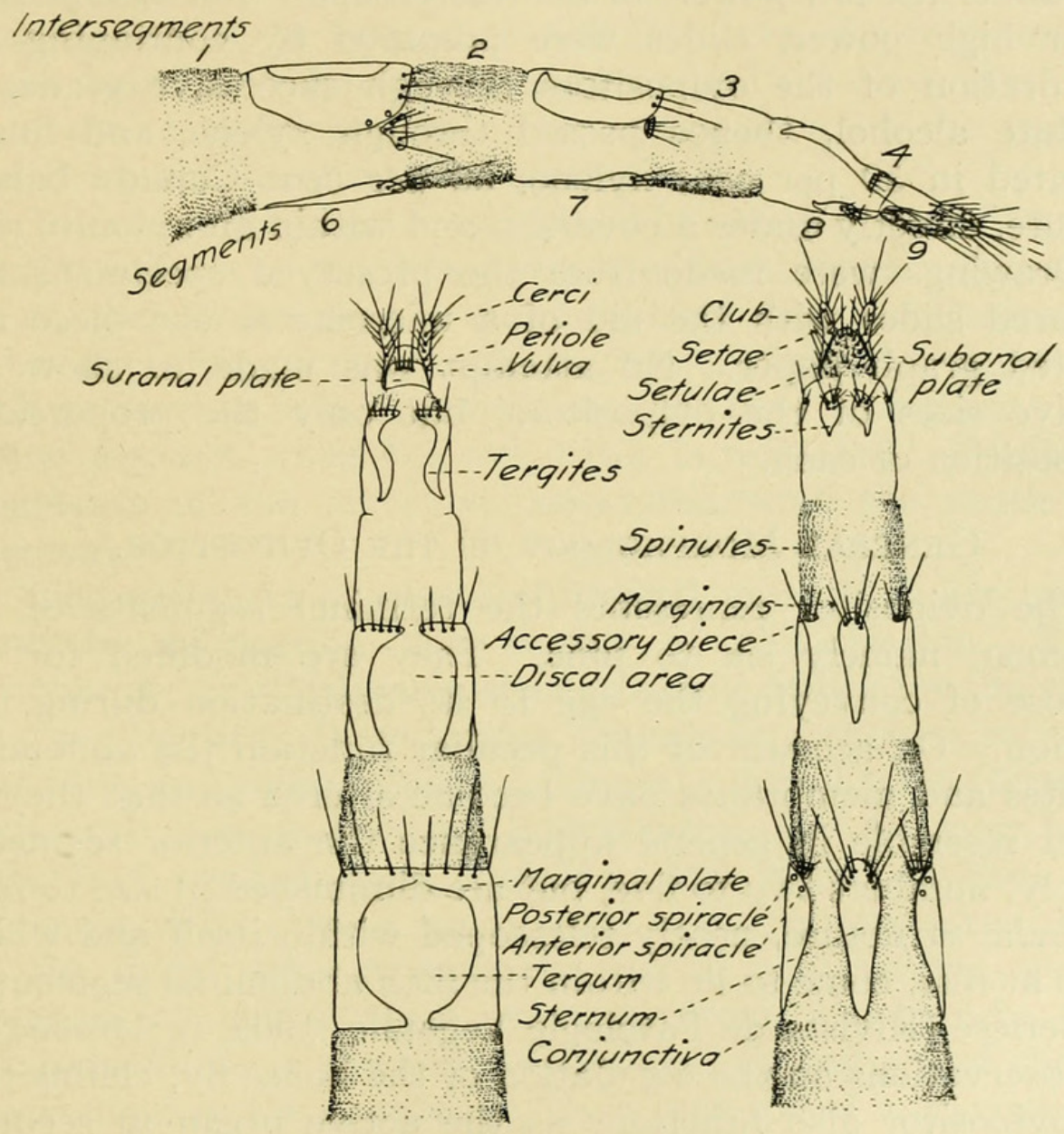

Technique.

The technique was of the simplest. The abdomen was transected in the region of the third abdominal segment with dissecting scissors. The excised portion was then placed in a 10 per cent solution of potassium hydroxide and left to soak until cleared. This time varied with different specimens from 
four hours to six days. Prior to removing the specimen from the solution the ovipositor was distended by lightly placing a blunt dissecting needle on the exposed portion of the ninth segment and with forceps or another needle gradually drawing away the excised portion of the abdomen from the point of attachment. This pulled out the ovipositor in a telescopic manner and allowed it a better opportunity of clearing. After thoroughly washing in water the ovipositors were placed in 50 per cent alcohol and run through the successive grades to 70 per cent, at which they were preserved for drawing and examination under the low powers of the microscope. For examination under high power, slides were prepared by continuing the dehydration of the ovipositors through successive grades to absolute alcohol, thence passed through xylene, and finally mounted in 50 per cent xylene, 50 per cent Canada balsam mixture, directly under a coverslip and within an xylonite ring.

Drawings were made from the preserved specimens and prepared slides with the aid of a micrometer eye piece and squared graph paper. No attempt was made to show the relative sizes of the ovipositors, but only the proportional composition of each.

\section{General Morphology of the Ovipositor.}

The ovipositor represents the terminal segments of the abdomen, namely six to nine. They are modified for the purpose of conveying the egg to its destination during oviposition. On account of this peculiar function the abdominal sclerites and membranes have become altered so that they no longer resemble in general appearance the anterior segments, namely, numbers two to five, but are diminished in size to form a tubular structure, neatly telescoped within itself and which, when at rest, come to lie within the fifth abdominal segment.

Berlese (Rivista de Patologie Vegetale, 1902, ix:345-354) in his observations on the copulation of the house fly, claims that the ovipositor also functions as the active organ in securing fertilization, the male organs being the meanwhile conspicuously inactive. Since the structure of the ovipositor and the male genitalia of Musca domestica Linn., and the following Anthomyian flies are essentially alike, especially with regards vestiture, it is not improbable that an additional function exists here also. 
The segments of the ovipositor are alternated by a well developed membrane known as the intersegments. The function of the latter is to provide a membranous sheath for the folding up of the segments and to increase the range of the ovipositor when necessary. The intersegments may be smooth, without vestiture, as in Pegomyia affinis Stein, Hylemyia lipsia W1k., and Chortophila longula Fallen, or covered with minute spines, partially or wholly. These recurrent spinules are sometimes arranged in transverse striæ, or as broad, imbricated spinules in no definite order, as in Chortophila parva R-D. caerulescens Strobl. and cinerella Fall. These spinules, although they appear to be limited to definite areas, yet frequently are to be found on adjacent membranes and sclerites, there being no definite demarkation. The annulations of the segments can, however, be always determined.

Intersegment nine is considerably reduced in size and dissimilar in form to the three preceding membranes. It functions as an attachment for the modified ninth segment (suranal and subanal plates) to the caudal margin of the eighth segment, as well as serving in a telescopic manner for the inclusion of the ninth segment when the ovipositor is retracted. Further the ligaments of the cerci are associated with the ninth intersegment.

The segments represent chitinized areas that are unstable both in delineation and degree of chitinization. Though functioning primarily as a strengthening device for the rigidity of the ovipositor, it undergoes changes in structure to provide elasticity and collapsability. Thus the dorsal plate (tergum) is frequently composed of two lateral pieces that are more heavily chitinized caudad than cephalad, and whose margins blend imperceptably into a mid-dorsal membranous area known as the discal area, or into the lateral conjunctivæ, ventrad. Degrees of chitinization, varying from a complete dorsal encasement, as in the abdomen proper, to vestiges of chitinous thickenings in the membrane, have been found in a series of the same species. This is thought to depend upon the age of the adult, degree of development, condition of pupation, etc., so that it is deemed inadvisable to put much credence in its taxonomic value.* The caudal margin of each tergum is

* The peculiar outline of the chitinous thickenings on segment eight in Chortophila brassica Bche, and antiqua Meig, have been so constant in the specimens under examination that it has been thought fit to make an exception of this case and to include this character in the key. 
surrounded by a row of setæ which in most cases is limited by the extent of the chitinization. In specific cases, short, hooklike setæ or stout spines replace the normal bristles. In segment six the posterior angles of the tergum possess two spiracles, orifices of a common trachea. On account of their position they are conveniently designated as the anterior and posterior spiracles. In segment six and seven the posterior angles of the tergum may become accentuated by a thinning of the chitin across those regions and the isolation of chitinous areas bearing numerous setæ. In such cases these areas have been designated as the accessory pieces.

The ventral plate (sternum) likewise varies in degree of chitinization, though not to the extent of the tergum. In segments six and seven the sternum usually consists of a long strip of chitin that tends to become indeterminate cephalad, sometimes this plate is limited to areas adjoining the caudal margin. The setæ border the caudal margin of the sternum in a row or are separated into two lateral groups. Similarly they are too replaced by stiff stout spines in certain cases. In segment eight the sternum is divided into two chitinous halves, more or less bilaterally symmetrical and known as the sternites. In general structure they present a hingelike appearance, overlapping the junction of the fourth intersegment with the conjunctiva of the eighth segment. In Chortophila cinerella Fall, and parva R-D, the sternites attain the whole length of the segment as two narrow rods of chitin. The setæ are to be found toward the caudal extremity, scattered irregularly, among which are often two of greater size and strength.

The lateral conjunctivæ of segments six, seven and eight are situated in a similar position to that of the segments of the abdomen, i. e., it consists of that part of the less chitinized cuticula, which is found between the sternum and tergum. Similar to the intersegments the conjunctivæ may be smooth or spinulose, or partly smooth, partly spinulose. The spinules may be arranged in indefinite transverse striæ or scattered irregularly throughout the membrane. The cephalic and caudal extents of the conjunctivæ are limited by the annulations of the segments.

Segment nine is modified to form the upper and lower lips of the anus The tergum or upper lip is composed of a single chitinous piece, hemispherical or scoopshaped, which is known 
as the suranal plate. It bears two strong setæ and a few spinelike setulæ. The sternum or lower lip is larger usually than the suranal plate and is composed of but one chitinous piece which is spade-shaped or broadly deltoid in outline. This sclerite is known as the subanal plate. Its surface is usually spinulose, rarely glabrous, and is clothed with numerous setulæ. At the apex and along the margins are to be found two pairs of strong setæ.

The cerci* are two subcylindrical anal appendages emerging from beneath and beside the suranal plate. They are composed of a distal half, which is club-shaped or knob-like, and a proximal half, which forms a stem for attachment and is termed the petiole. Sometimes the cerci are sessile, plate-like or pubescent. The apex of each club bears one to three long setiform hairs and two or more setiferous sense organs, hautsinnesorgane. The latter are tubercular in form, each of which is armed with a short, sharp spine at the apex, or is large and disc-like, from the center of which emerges a fine hair-like papilla. The remaining surface of the cerci is clothed with numerous stout setulæ.

\section{LIST OF SPECIES.}

Genus Chortophila Macquart.

C. antiqua Meigen.

C. brassicæ Bouché.

C. caerulescens Strobl. $\dagger$

C. candens Zetterstedt. $\ddagger$

C. cilicrura Rondani.

C. cinerella Fallen.

C. dissecta Meigen. $\dagger$

C. fugax Meigen. $\dagger$

C. grisella Rondani. $\dagger$

C. laevis Stein. $\$$

C. longula Fallen. $\dagger$

C. muscaria Meigen.

C. nuda Strobl. $t$

C. parva Desvoidy.

C. rubivora Coquillett.

C. substriata Stein.
Genus Hylemyia Desvoidy.

$\mathrm{H}$. aemene Walker.

H. alcathoe Walker.

H. coarctata Fallen. $\dagger$

H. flavicans Stein.

H. flavipennis Fallen. $\dagger$

$\mathrm{H}$. juvenilis Stein.

H. lipsia Walker.

H. setiventris Stein.

H. strigosa var. nigrimana Fabricius. $\ddagger$

H. variata Fallen.

Genus Pegomyia Desvoidy.

P. affinis Stein.

P. calyptrata Zetterstedt.

P. hyoscyami Panzer.

P. trilineata Stein.

P. trivittata Stein.

P. unicolor Stein.

P. winthemi Meigen.

* The term cerci has been chosen from a number of names given by authors as least likely to produce confusion. On the other hand there appears to be little doubt but that these anal appendages are tactile and not prehensile in function and for the sake of explicitness and accuracy would better be designated as anal palpi.

$\dagger$ See note under Description of ovipositors.

$\ddagger$ European specimens.

$\S$ Specimen closely resembles laevis Stein. 


\section{DESCRIPTION OF OVIPOSITORS.}

An asterisk qualifying the name of a species signifies that the specimen keys out to that species in Stein's key (1914) to the females of European Anthomyida.

\section{Genus Chortophila Macquart.}

\section{Chortophila antiqua Meigen.}

Segments and intersegments of equal length, sclerites glabrous, except the subanal plate which is spinulose. Intersegments one, two, and three spinulose, fourth smooth.

Segment VI. Tergum in structure and character similar to cilicrura, usually more heavily chitinized, the discal area appearing yellowish; accessory pieces present; marginals diverse, in an irregular row; spiracles approximate, barely the width of the sternum apart, in the same straight linet, posterior spiracles cephalad of the accessory pieces. Sternum somewhat pegshaped, the cephalic half narrowed to a blunt point which attains the cephalic margin; setæ grouped apart around the caudal margin; conjunctiva smooth, with chitinous thickenings.

Segment VII. The tergum similar to that of segment VI, the tergites less chitinized; accessory pieces present. Sternum lanceolate, tapering to a blunt point on the cephalic margin, flaring caudad; marginals distributed in a broad semicircle along the caudal border; conjunctiva as in segment VI.

Segment VIII. Tergum divided bilaterally, the tergites strongly chitinized along the caudal margin of the segment as in cilicrura; the sclerites proceed dorsocephalad as undulating plates, scarcely attaining the cephalic margin; marginals diverse, more numerous than in cilicrura, regularł. Sternum composed of two ovoid sclerites, but one-half the length of the segment; setæ diverse, scattered caudad; conjunctiva smooth, studded with chitinous knobs.

Segment IX. Suranal plate scoop-shaped; setæ less than the width of the club apart; subanal plate spinulose, spade-shaped to triangular; setæ long, fine, hairlike, bounding the apical third of the sclerite, setulæ diverse; cerci glabrous, club compact, petiole short; setæ composed of one long apical and three or four shorter, besides long spinelike setulæ.

\section{Chortophila brassicæ Bouché.}

Segments and intersegments of equal length, sclerites glabrous except the subanal plate which is spinulose. Intersegments spinulose except for the fourth whose ventral surface is smooth.

Segment VI. Tergum divided bilaterally, the tergites border the caudal and cephalic margins, in the former case the sclerites tend to fuse across the mid dorsal line, ventral and dorsal margins indeterminate; discal area slightly chitinized blending imperceptibly with the

$\dagger$ As opposed to oblique.

$\ddagger$ Regular $=$ In a single row. 
adjoining sclerites; accessory pieces absent; marginals diverse, regular; spiracles approximate, the width of the sternum apart, oblique, $\dagger$ posterior spiracles cephalad of the caudal margin. Sternum lanceolate, tapering to both margins; marginals approximating, in pairs; conjunctiva smooth, ornamented with rough chitinous thickenings.

Segment VII. Similar to segment VI in structure, the tergites less extensive along the margins; discal area well marked, roughened by chitinous thickenings; marginals diverse, regular; accessory pieces absent. Sternum lanceolate, tapering cephalad, rounded caudad; marginals approximate; conjunctiva, smooth, chitinized.

Segment VIII. Tergum divided bilaterally into two irregular plates somewhat similar to those of the corresponding segment in antiqua except that the dorsal surface of the lateral plates becomes more markedly sinuous giving the discal area a decided constriction at the middle; marginals short, regular, with strong lateral setæ. Sternum similar in structure and character to that of antiqua setæ distributed over the entire surface, two strong, remainder short spinelike; conjunctiva smooth, chitinized.

Segment IX. Suranal plate scoop-shaped; setæ barely the width of the club apart, setulæ few; subanal plate spinulose, spade-shaped to conical, setæ apart, a fringe of setulæ around the margin, surface covered with short spinelike setæ; cerci smooth, petiolate, conical to subcylindrical; apicals long, setæ diverse, long, fine, more abundant than in cilicrura or antiqua, clothing the club and petiole; sense organs two, apical, papillæ short.

\section{Chortophila cærulescens Strobl.*}

Segments and intersegments of equal length, sclerites glabrous except for the subanal plate which is spinulose. Intersegments spinulose, each successive membrane from the first to the third becoming more densely spined; spinules broad at their bases giving the appearance on the third intersegment of being clothed with scales, similar to cinerella and parva.

Segment VI. Tergum composed of two lateral plates each shaped like an inverted " $\mathrm{L}$," somewhat flaring along the caudal margin, tapering cephalad; accessory pieces present, distinct; marginals few, two or three, equal, $\ddagger$ distributed dorsad; discal area hyaline, membranous, occupying the greater part of the tergal region; spiracles closely approximate, directly cephalad of the accessory pieces, posterior spiracles of greater diameter than the anterior and situated slightly oblique. Sternum much reduced, a small quadrangular sclerite adjacent to the caudal margin, pointed cephalad; marginals separated into two lateral groups of a few setæ each; conjunctiva smooth, hyaline.

Segment VII. Tergum composed of two narrow lateral tergites whose form is maintained undiminished to the cephalic margin, caudad the ventral borders are rounded off so that the marginal plates are lim-

$\dagger$ Oblique $=$ Spiracles placed at an angle to the longitudinal axis of the insect.

$\ddagger$ Equal= The same in size and length. 
ited to a short dorsal curve; accessory pieces present, distinct; marginals few, similar in distribution to segment VI; discal area hyaline. Sternum much reduced, funnel form; marginals separated into two lateral groups of a few setæ each, usually two; conjunctiva smooth, hyaline.

Segment VIII. Tergum composed of two lateral plates whose caudal expansions fuse across the mid-dorsal line and extend slightly ventrad; cephalad the tergites approximate slightly; discal area smooth, hyaline; marginals equal, regular, sparsely distributed. Sternum composed of two heavily chitinized, lanceolate plates, attaining threequarters the length of the segment, similar to cilicrura; setæ few distributed on the apical area; conjunctiva smooth, hyaline.

Segment IX. Suranal plate scoop-shaped; setæ short and stout, wide apart, equal to the breadth of a club; setulæ few: subanal plate spinulose, bell-shaped; setæ limited to the apical region; setulæ numerous, equal, short and thornlike, distributed over the inner surface, the outer margin being bare; cerci glabrous, knoblike, short petiole; setæ few, sparesly distributed, apicals short, one per club; sensory organs two, contiguous, situated at the apex, domelike.

\section{Chortophila candens Zetterstedt. $\dagger$}

Segments slightly longer than the intersegments, broader than long, more heavily chitinized along the cephalic than on the caudal margins; sclerites glabrous, except the subanal plate which is spinulose. Intersegments spinulose except the fourth which is smooth.

Segment VI. Tergum composed of two broad quadrangular lateral plates, dorsal and ventral borders indefinite; discal area lightly chitinized, blending imperceptibly with the lateral plates, widely separating the tergites for the most part; accessory pieces present; marginals diverse, numerous, closely distributed along the caudal margin of the segment; spiracles oblique, separated by the caudal margin of the segment, the posterior spiracles opening on the second intersegment. Sternum vasiform, heavily chitinized cephalic half, lightly chitinized caudal half; marginals approximate, bordering the caudal margin; conjunctiva spinulose.

Segment VII. Tergum similar in character and structure to segment VI, except that the spiracles and accessory pieces are absent; marginals numerous, closely distributed, discal area thinly chitinized. Sternum lanceolate, the borders indeterminate; marginals bordering the caudal margin; conjunctiva spinulose, indistinctly striated.

Segment VIII. Tergum composed of two quadrangular lateral plates, the caudal margin oblique, constricting the ventral borders to but one-half the length of the segment, cephalic margins strongly chitinized, approximating dorsad so as to enclose the discal area; discal area thinly chitinized, imperceptibly blending into the lateral plates; marginals equal, closely distributed along the caudal margin of the segment, a group of strong setæ situated at the caudo-ventral angles of the tergum. Sternum composed of two short ovoid sternites on which are distributed numerous stout heavy spines; conjunctiva smooth.

$\dagger$ European specimen. 
Segment IX. Suranal plate scoop-shaped, the basal angles narrowly produced ventrad; armed with four strong curved spines; subanal plate fanshaped; setæ long, hairlike; setulæ dense, fine and hairlike, at the basal angles are found a group of fine, strong bristles; cerci glabrous, modified into a pair of thin chitinous plates that border the lateral regions of the anus and closely articulate with the concave margins of the suranal plate; each is armed with two heavy upcurving apical spines in addition to numerous shorter spines of a similar nature, a few long, fine hairs on the apical region interspersed amongst the spines.

Chortophila cilicrura Rondani.

Segments and intersegments of equal length, sclerites glabrous, except the subanal plate which is spinulose. Intersegments spinulose, densely striated.

Segment VI. Tergum divided bilaterally; the caudal and cephalic boundaries of the tergites concur with the margins of the segment, the dorsal border merges into a semi-opaque discal area, which is spotted with chitinous thickenings; accessory pieçes present; marginals few, diverse, regular; spiracles wider apart than the breadth of the sternum, slightly oblique, posterior spiracles bordering the caudal margin. Sternum, a narrow mid-ventral plate reaching both margins of the segment, flaring slightly caudad, tapering cephalad; marginals continued along the lateral margins; conjunctiva spinulose, densely striated.

Segment VII. Similar in structure and character to segment VI; marginal plates of the tergites somewhat constricted caudad; sternal marginals separated into two lateral groups.

Segment VIII. Tergum divided bilaterally; marginal plates strongly chitinized, which extend as lateral plates dorsocephalad thereby constricting the cephalic extent of the discal area. The latter is marked by chitinous thickenings; marginals diverse, regular. Sternum composed of two elongate sternites, but two-thirds the length of the segment; setæ spine-like, scattered about the caudal areas; conjunctiva smooth, throughout ornamented by knoblike thickenings of chitin.

Segmerit IX. Suranal plate scoopshaped; setæ the width of the club apart; subanal plate spinulose, spade-shaped, setæ normal; $\dagger$ setulæ sparsely distributed; cerci glabrous, club or cone-shaped, petiolate; setæ composed of one long apical and two shorter, besides a few setulæ scattered on the club and petiole.

\section{Chortophila cinerella Fallen.}

Segments and intersegments of equal length, sclerites glabrous except the subanal plate which is spinulose. Intersegments spinulose, covered with broad, straight spinules that give the membranes the appearance of being clothed with scales.

Segment VI. Tergum composed of two broad lateral plates, crescentshaped, separated by a wide hyaline discal area; accessory pieces pres-

$\dagger$ Normal $=$ Setæ consisting of an apical pair approximate, and a preapical pair, wide apart, situated on the margins. 
ent; marginals few; spiracles contiguous, slightly oblique, directly cephalad of the accessory pieces. Sternum reduced to two round chitinous areas that have fused and lie adjacent to the caudal margin of the segment; marginals wide apart, arranged into two groups; conjunctiva hyaline, transparent.

Segment VII. Tergum composed of two narrow chitinous strips, flaring caudad and extending the length of the segment along the subdorsal axes; discal area hyaline; accessory pieces present; marginals few and stout. Sternum, similar in structure to segment VI, pointed cephalad; marginals widely separated into two groups; conjunctiva hyaline.

Segment VIII. Tergum similar in structure to that of segment VII; the tergites broaden more noticeably caudad; marginals more numerous; discal area hyaline transparent, the sides of the segment clothed for the greater part with scalelike spinules. Sternum composed of two narrow sternites, oar-shaped, subparallel, extending along the subventral axes for the length of the segment; setæ two; conjunctiva hyaline.

Segment IX. Suranal plate hemispherical; setæ stout, setulæ few; subanal plate spinulose, spade-shaped, setæ normal; setulæ sparsely distributed; cerci small, glabrous, knoblike; setæ consist of one strong apical seta, setulæ spinelike.

\section{Chortophila dissecta Meigen.*}

Segments slightly longer than the intersegments, breadth exceeds length. Intersegments; vestiture not uniform, first intersegment spinulose, second and third the ventral surface spinulose with narrow dorsal stripes along the cephalic margins, fourth intersegment spinulose on the ventral surface, smooth dorsal region.

Segment VI. Tergum spinulose, composed of two broad enveloping plates that are linked together across the mid-dorsal line by a thinly chitinized discal area; accessory pieces present; marginals diverse, arranged in an irregular row; spiracles, the width of the accessory piece apart, oblique, posterior spiracles close to the caudal margin of the segment. Sternum spinulose, expansive, whose margins are indeterminate, gradually fading into the surrounding membrane; marginals diverse, scattered about the caudal border; conjunctiva spinulose.

Segment VII. Tergum glabrous, divided into two lateral plates, each extensively bordering the caudal margin, almost fusing across the mid-dorsal line, thence forward gradually tapering to a rounded apex, not quite reaching the cephalic margin of the segment; discal area hyaline, smooth, widely separating the tergites cephalad; accessory pieces present; marginals diverse arranged in an irregular, row. Sternum spinulose, a short, indeterminate plate; marginals in a transverse row; conjunctiva spinulose, on the mid-ventral line adjacent to the cephalic margin is found a small chitinous thickening bearing two stout spinules.

Segment VIII. Tergum glabrous, composed of two lateral pieces whose caudal margins have fused dorsad to form a marginal plate, the tergites extend dorsocephalad toward the cephalic margin, bordering a smooth, hyaline discal area; marginals diverse, in an irregular row. 
Sternum glabrous, ovoid, pointed caudad; setæ diverse, few, distributed over the sclerites; conjunctiva smooth, hyaline.

Segment IX. Suranal plate glabrous, scoop-shaped; setæ approximate, less than the width of the club apart, long, exceeding by twice the length of the plate, few setulæ; subanal plate spinulose, spadeshaped; marginals long, setulæ sparsely distributed; cerci sparsely spinulose, conical to subcylindrical, petiolate, setæ consist of three long apicals and numerous bristlelike setulæ distributed on the petiole and club; sense organs, tubercular, situated laterad.

\section{Chortophila fugax Meigen, and substriata Stein.*}

Segments longer than the intersegments, breadth exceeds length. Intersegments spinulose.

Segment VI. Tergum glabrous, completely chitinized, encasing the whole region, ventral margins protruding; marginals few, diverse, unevenly distributed, continuing along the ventral margin; accessory pieces absent; spiracles the width of the sternum apart, oblique, posterior spiracle considerably dorsad of the anterior one, in the region of the caudal margin of segment. Sternum spinulose, spatulate, extending the length of the segment; marginals in two separate groups along the lateral margins; conjunctiva spinulose.

Segment VII. Tergum glabrous, completely chitinized as in segment VI; discal area vestigial; marginals diverse, distributed irregularly around the caudal margin; accessory pieces absent. Sternum spinulose, spatulate, thinly chitinized cephalad, marginals wide apart, grouped laterad; conjunctiva spinulose, striated.

Segment VIII. Tergum, caudal half spinulose, cephalic half glabrous, completely chitinized across the tergal region; marginals equal, irregularly distributed. Sternum spinulose, elongate; setæ sparsely distributed over the surface; conjunctiva spinulose.

Segment IX. Suranal plate spinulose, scoop-shaped, setæ very long, $21 / 2$ times the length of plate; setulæ few; subanal plate, broad, spadeshaped, spinulose; marginals short, setulæ equal, numerous; cerci spinulose, setulæ short; sense organs, two contiguous, one separate.

\section{Chortophila grisella Rondani.*}

Segments and intersegments of equal length, sclerites glabrous except the subanal plate which is spinulose. Intersegments smooth, without vestiture, in common with the segmental membranes ornamented with chitinous granulations.

Segment VI. Tergum somewhat similar in structure to antiqua, the lateral plates expand along the caudal and cephalic margins almost fusing across the mid-dorsal line; discal area semi-opaque, coarsely granulated; marginals short, equal, regular, terminating on either side in a strong setæ; spiracles the breadth of the sternum apart, oblique, the anterior spiracles dorsad of the posterior, the latter twice the size of the former and situated at the bases of the strong marginal setæ; accessory pieces absent. Sternum reduced to a small cordate sclerite adjacent 
to the caudal margin; marginals few, wide apart; conjunctiva coarsely granulated.

Segment VII. Tergum divided into two lateral plates whose caudal extremities expand to form marginal plates; discal area hyaline; marginals few, regular, with strong lateral bristles; accessory pieces absent. Sternum reduced to a small, ovoid sclerite adjacent to the caudal margin, the apices pointed, marginals wide apart, few; conjunctiva roughened.

Segment VIII. Tergum yoke or collar-shaped, the tergites illdefined with ragged borders that blend irregularly into the less chitinized semi-opaque discal area, a distinguishable, interrupted chitinous thickening along the mid-dorsal line that merges finally with the fused caudal pieces. The caudal margin of the segment, as in rubivora, is only recognized by the marginals due to the fusing of the heavily knobbed chitinous area of the fourth intersegment with the tergum which obliterates any definable line; marginals equal, regular with pronounced lateral setæ. Sternum consists of two small, ovoid sclerites, tapering caudad; setæ diverse, scattered over the entire surface.

Segment IX. Suranal plate scoop-shaped, setæ approximate, strong; subanal plate spinulose, spade-shaped, setæ widely separated, hairlike, setulæ short, equal, distributed over the surface; cerci smooth, knobbed, long slender petiole; apicals long and fine, setulæ diverse, confined to the club; sense organs four.

\section{Chortophila lævis Stein. $\dagger$}

Segments nearly twice the length of the preceding intersegment. Intersegments, spinulose, densely striated.

Segment VI. Tergum undivided, encasing the dorsal surface as a shield, the chitin semi-opaque and somewhat thinner toward the middorsal line on which region it is lightly spined; accessory pieces absent; marginals diverse, scattered irregularly around the caudal margin, continuing cephalad in a single row along the ventral border; spiracles twice the breadth of the sternum apart, slightly oblique, the posterior spiracles on the caudal margin of the segment; area bounded by the caudo-ventral angles clothed with a few fine spinules. Sternum spinulose, club-shaped, the cephalic half but lightly chitinized; marginals distributed along the lateral borders for some distance; conjunctiva covered densely with short spinules.

Segment VII. Similar in structure to segment VI; spinules thinly distributed over the tergal and sternal surfaces; discal area almost obliterated; marginals diverse, distributed irregularly along the caudal border; accessory pieces absent. Sternum spatulate, the cephalic half attenuated and but lightly chitinized; marginals distributed along the lateral margins; conjunctiva densely spinulose, striated.

Segment VIII. Tergum composed of a fused marginal plate which extends as two lateral pieces, gradually tapering toward the cephalic margin; discal area thinly chitinized, merging imperceptibly with the chitin of the lateral plates; margins short, diverse, regular. Sternum

\footnotetext{
$\dagger$ Probably a new species though closely resembling laevis.
} 
spinulose, narrow sclerites that attain two-thirds the length of the segment; setæ few, diverse; conjunctiva, spinulose, the cephalic margin of the segment bordered by spinules throughout.

Segment IX. Suranal plate glabrous, scoop-shaped, setæ very long; subanal plate spinulose, spadelike, setæ normal, fairly long; setulæ sparsely distributed; cerci glabrous, small, knoblike, petiolate; setæ short, stout, two or three apicals on each cercus, setulæ short, bristlelike confined to the club.

\section{Chortophila longula Fallen.*}

Segments and intersegments of equal length, sclerites glabrous except the subanal plate which is spinulose, marginals of the terga equal, evenly distributed in a single row along the caudal margin of the segments. Intersegments smooth, hyaline, transparent, except the base of the first intersegment which is spinulose.

Segment VI. Tergum lightly chitinized, encasing the dorsal region as a homogeneous plate, except for the ill-defined notch-like discal area which partitions the cephalic margin; accessory pieces present; spiracles closely approximate, oblique, near to the caudal margin. Sternum lanceolate, attaining half the length of the segment; marginals few, separated into two groups; conjunctiva smooth, with slight chitinous granulations.

Segment VII. Tergum composed of a strong marginal plate, from the lateral boundaries of which extend two chitinous plates cephalad. At times there develops along the mid-dorsal line a median chitinous thickening; discal area hyaline; accessory pieces present. Sternum reduced to a short, oblong plate, about half the length of the segment; marginals few, wide apart; conjunctiva smooth, with chitinous thickenings.

Segment VIII. Tergum similar in structure to segment VII, the lateral plates slightly undulating and taper gradually toward the cephalic margin; discal area hyaline, sometimes divided by a median chitinous thickening. Sternum composed of two short tapering plates adjoining the caudal margin; setæ few; conjunctiva, smooth, hyaline.

Segment IX. Suranal plate scoop-shaped; setæ wide apart, exceeding the breadth of the club by twice; setulæ five or six, between the setæ; subanal plate spinulose, spade-shaped; setæ distributed along the margin; setulæ diverse; cerci smooth, conical, petiolate; setæ short, apicals strong; setulæ few; sense organs four, contiguous, situated towards the apex of each cercus.

\section{Chortophila muscaria Meigen.}

Segments longer than the intersegments; marginals long, diverse, scattered around the caudal margin of the segments. Intersegments spinulose, except for the dorsal region of the fourth which is reduced to a hyaline transverse strip; the remaining membranes are densely spinulose, the spinules increasing in size from the first to the third intersegment; similarly a clear membranous strip defines the caudal margins 
of intersegments one to three, which increases in width and proportion according to succeeding intersegments.

Segment VI. Tergum glabrous, composed of two broad lateral plates whose caudal margins approximate, almost fusing across the mid-dorsal line, dorsal and ventral borders ragged, indeterminate; discal area gradually widening cephalad, hyaline, indefinitely striated by rows of spinules; accessory pieces absent; marginals long, diverse, distributed in two irregular rows; spiracles wide apart, equalling twice the breadth of the sternum, oblique, posterior spiracles situated on the caudal margin. Sternum lanceolate, extending for three-quarters the length of the segment, spinulose posteriorly; marginals approximate, scattered, including two very long setæ; conjunctiva spinulose, spinules very small and dense, short fine spines sparsely distributed about the caudal area.

Segment VII. Tergum glabrous, somewhat similar in structure to segment VI, heavily chitinized along the lateral and caudal margins, investing a coarsely spinulated discal area; marginals diverse, distributed around the caudal margin irregularly. Sternum, lanceolate, attaining the whole length of the segment, gradually tapering to a point caudad; marginals few, including two very long setæ; conjunctiva densely spinulose, short, fine spines sparsely distributed about the caudal area.

Segment VIII. Tergum composed of a heavily chitinized, archlike plate, partially enclosing a lightly chitinized, spinulose discal area; the lateral plates spinulose cephalad, smooth throughout the caudal half; marginals numerous, short, spinelike, scattered across the marginal plate. Sternum smooth, composed of two narrow chitinous sclerites, broadened toward the cephalic margin thence gradually tapering to a fine point caudad; setæ few, one or two; conjunctiva spinulose.

Segment IX. Suranal plate triangular, equilateral, larger than the subanal plate; setæ approximate, closer together than the width of the club; subanal plate spinulose, smaller than the suranal plate; setæ arranged in a semi-circle, bordering the margin; setulæ numerous, distributed over the entire surface; cerci short, smooth, laterally compressed, sessile; setæ short and fine; apicals two; sense organs two, situated laterad.

\section{Chortophila nuda Strobl**}

Segments and intersegments of equal length, sclerites glabrous except for the subanal plate which is spinulose. Intersegments densely spinulose, striated, except for the ventral surface of intersegment four which is smooth.

Segment VI. Tergum composed of two broad lightly chitinized lateral plates that blend gradually into the more or less constricted discal area, ventral margin defined; accessory pieces present; marginals diverse, few, evenly distributed, regular; spiracles wide apart, the breadth of the sternum, situated along the ventral margin. Sternum, elongate sclerite, rounded caudad, gradually tapering cephalad to the margin; marginals approximate, around the caudal border. 
Segment VII. Tergum similar in structure to segment VI, the caudal margin somewhat constricted; accessory pieces present, distinct; marginals few; discal area membranous, hyaline. Sternum lanceolate, rounded caudad, tapering to a point cephalad, attaining the length of the segment; marginals separated into two lateral groups; conjunctiva lightly spinulose.

Segment VIII. Tergum composed of two lateral plates which flare caudad so as to envelop the margin, cephalad the plates curve dorsad, approximating at the cephalic margin; discal area with chitinous granulations, constricted cephalad; marginals equal, distributed regularly in a single row. Sternum, two small ovoid sclerites bordering the caudal margin; setæ strong, spinelike, scattered throughout; conjunctiva smooth.

Segment IX. Suranal plate scoopshaped; setæ approximate, less than the width of the club apart, setulæ few; subanal plate spadeshaped; setæ equidistant, bordering the apical margin, setulæ spinelike, distributed over the surface; cerci clubbed, petiolate, smooth; apicals two or three, setulæ long, diverse; petiole smooth; sense organs, two apical tubercles.

\section{Chortophila parva Desvoidy.}

Segments slightly longer than the intersegments, sclerites glabrous except the subanal plate which is spinulose. Intersegments spinulose, increasing in density according to successive intersegments, spinules broad at their base, not recurrent, becoming much coarser in intersegment three; structure and character very similar to cinerella and carulescens scalelike in appearance.

Segment VI. Tergum denoted by a chitinized caudal half and a clear hyaline cephalic half, the caudal region composed of two bilaterally symmetrical plates, somewhat crescentshaped, bounding a clear hyaline discal area; accessory pieces present; marginals few, short, usually two; spiracles closely approximating, in a horizontal plane, side by side, directly cephalad of the accessory pieces. Sternum reduced to a small pear-shaped sclerite adjacent to the caudal margin; marginals separated and arranged in two lateral groups; conjunctiva smooth, hyaline.

Segment VII. Tergum composed of two chitinous rods situated subdorsad, from the caudal to the cephalic margins; at the extremities the rods tend to approximate, constricting the long hyaline discal area; accessory pieces present, distinct; marginals few, short, usually two, distributed dorsad. Sternum reduced to a small triangular sclerite adjacent to the caudal margin; marginals separated into two groups, wide apart; conjunctiva smooth, hyaline.

Segment VIII. Tergum composed of two chitinous rods, subdorsad, that expand at their caudal extremities to invest the margin of the segment, cephalad the rods approximate reaching the cephalic margin; marginals few, short, bristlelike, regular. Sternum similar in structure to 
the tergum, the sternites extend along the subdorsal axes, tapering to a point caudad; marginals short, bristlelike; conjunctiva hyaline, transparent, the caudal half of the lateral membranes clothed with dense, broad spinules, scalelike.

Segment IX. Suranal plate broad, scoop-shaped, setæ strong, the width of the club apart; subanal plate spinulose, broadly conical, setæ short, in a transverse row across the apical third, setulæ small, thornlike; cerci smooth, knoblike, sessile; setæ few, apicals stout, setulæ bristlelike; sense organs two, contiguous, papillæ of medium length, not domelike.

\section{Chortophila rubivora Coquillett.}

Segments and intersegments of equal length. Sclerites glabrous. Intersegments densely spinulose except the fourth which is smooth but for a few spinules along the cephalic margin of the dorsum.

Segment VI. Tergum an unevenly chitinized plate which presents two lateral thickenings and a thinly chitinized mid dorsal region; discal area indeterminate; marginals diverse, regular; spiracles closer together than the width of the sternum, oblique, posterior spiracle cephalad of the caudal margin; accessory pieces absent. Sternum broadly lanceolate, tapering at both extremities to the margins of the segment; marginals approximating, continued for a short distance along the lateral borders; conjunctiva spinulose, densely covered.

Segment VII. Tergum similar in structure to segment VI except that the chitin is thinner and tends to separate the tergum into two lateral, thickened plates; discal area vestigial; marginals diverse, somewhat irregularly arranged; accessory pieces absent. Sternum lanceolate, tapering to both margins, marginals approximate; conjunctiva spinulose.

Segment VIII. Tergum composed of two lateral chitinous plates which have fused along the caudal margin across the mid-dorsal line. Frequently a tonguelike chitinous thickening appears on the discal area which fuses caudad with the marginal plate; discal area chitinized; marginals short, spinelike, regular, denoting the fusion of the firmly chitinized fourth intersegment with the caudal margin of the segment with which it appears to form an integral part, similar in structure to substriata. Sternum composed of two narrow sternites that attain three-quarters the length of the segment, pointed caudad; setæ few, short, spinelike; conjunctiva spinulose.

Segment IX. Suranal plate triangular; setæ approximate, strong, the base of the plate closely coincident with the margin of the fourth intersegment; subanal plate, smooth, spadelike to conical; marginals apart, a fringe of setulæ around the apex, the surface sparsely covered with setulæ; cerci smooth, clavate, petiolate; apicals long, setulæ covering club and petiole; sense organs two, contiguous, subapical. 


\section{Genus Hyle yia Desvoidy.}

\section{Hylemyia æmene Walker, flavicans Stein and alcathœ Walker.}

Up to the present no accountable differences are to be observed in the structure, vestiture or chætotaxy of the three above named species. The three species in common may therefore be treated under the same description.

Segments and intersegments of equal length, sclerites glabrous except the subanal plate which is spinulose. Intersegments spinulose on the ventral surface except the fourth which is smooth throughout, on the dorsal surface intersegments one, two and three spinulose along the cephalic margins and for a greater or less distance along the region of the mid-dorsal line, remaining area smooth, hyaline.

Segment VI. Tergum completely chitinized, encasing the dorsal region, cephalic border indeterminate; accessory pieces absent; marginals diverse, regular; spiracles oblique, the width of the sternum apart, posterior spiracle on the caudal margin. Sternum lanceolate to pegshaped, tapering to a blunt point on the cephalic margin, truncate caudad; marginals approximate; conjunctiva spinulose on the caudal half, smooth cephalad.

Segment VII. Tergum similar in structure to segment VI, thinly chitinized on the discal region; marginals diverse, regular. Sternum pegshaped, tapering cephalad; marginals bordering the caudal margin; conjunctiva, caudal third spinulose, remaining surface smooth.

Segment VIII. Tergum composed of two lateral plates which tend to approximate toward the cephalic margin, gradually tapering to a point, caudad the extremities flare and coincide with the margin, nearly fusing across the mid-dorsal line; discal area broad, hyaline; marginals diverse, regular. Sternum composed of two broadly ovoid sclerites that taper to a point at both ends, attaining one-half the length of the segment; setæ distributed over the surface irregularly; conjunctiva smooth.

Segment IX. Suranal plate scoop-shaped; setæ strong, approximate, setulæ strong, spinelike; subanal plate spade-shaped to conical; setæ long; setulæ beside the margins long, remainder short; cerci smooth, petiolate, club clavate to subcylindrical, clothed with long fine setulæ, apicals long and fine; sense organs apical, consist of two large membranous discs from which emerge fine hairlike papillæ, also two small spined tubercles, the former give the club a truncate or "chipped" appearance.

\section{Hylemyia coarctata Fallen.*}

Segments and intersegments of equal length, sclerites glabrous except the subanal plate which is spinulose. Intersegments spinulose on the ventral and smooth on the dorsal surfaces except for the fourth, which is smooth throughout.

Segment VI. Tergum composed of one thinly chitinized plate encasing the dorsal region, cephalic margin indeterminate; accessory pieces present; marginals few, equal, regular; spiracles the width of 
the sternum apart, slightly oblique, posterior spiracles situated on the accessory pieces. Sternum lanceolate, attaining the length of the segment, expanding before tapering to the cephalic margin; marginals approximating, distributed for a short distance along the lateral borders; conjunctiva spinulose.

Segment VII. Tergum similar in structure and character to segment VI, a more noticeable thinning of the chitin dorsad. Sternum with rounded caudal margin; the marginals arranged in a semi-circle around the border; conjunctiva smooth.

Segment VIII. Tergum similar in structure to amene, composed of two lateral plates whose caudal extremities flare and adhere to the margin, cephalad the plates slightly approximate, tapering toward the cephalic margin; discal area hyaline, spaceous; marginals diverse, regular. Sternum composed of two broadly ovoid sclerites tapering to a point caudad, attaining one-half the length of the segment; setæ distributed over the entire surface, bristlelike; conjunctiva smooth.

Segment IX. Suranal plate scoopshaped; setæ barely the width of the club apart; setulæ few, strong; subanal plate spade-shaped; setæ regular; setulæ around the margin spinelike, remainder shorter; cerci conical to subcylindrical, clothed with fine long setulæ, apicals long and fine; sense organs consist of two large membranous discs from which emerge fine hairlike papillæ and two small tubercles, the former cause the apices of the clubs to appear chipped or notched.

\section{Hylemyia flavipennis Fallen.*}

The structure and character of the segments and intersegments are very similar to those of coarctata. In flavipennis the length of the segments and intersegments is equal to their breadth; the accessory pieces are absent, and the shape of the ventral sclerites vary slightly from that of coarctata. In flavipennis the caudal border of the sternum of the sixth segment is truncate with the marginals arranged along the caudal margin whereas in coarctata the caudal extremity tapers to a point with the marginals arranged laterad. The conjunctiva of the sixth segment in flavipennis is spinulose on the caudal third and smooth for the remaining area whereas in coarctata the whole surface is spinulose. The sternum of the seventh segment of flavipennis tapers cephalad, in coarctata the cephalic half of the sclerite expands before reaching the margin. Further in flavipennis the setæ of the suranal plate lie closer to each other.

\section{Hylemyia juvenilis Stein.}

Segments one and two slightly longer than the foregoing intersegments, segment VIII equal to intersegment three; suranal, subanal plates and cerci densely pubescent. Intersegments spinulose except the fourth which is smooth throughout.

Segment VI. Tergum glabrous, completely chitinized, shieldlike, encasing the tergal region; accessory pieces absent; marginals diverse, regular, continuing for a short distance along the ventral border; spiracles barely the width of the sternum apart, oblique, posterior spiracles 
cephalad of the caudal margin. Sternum spatulate or paddle-shaped, the blade covered with dense minute spines, marginals distributed along the lateral borders; conjunctiva densely spinulose.

Segment VII. Tergum similar in structure to segment VI, the chitin less dense toward the mid-dorsal region, cephalic margin ragged, incised; marginals confined to the caudal border. Sternum spatulate, unevenly chitinized, the outline at times interrupted, clothed with dense minute spines around the caudal margin; marginals even, distributed laterad; conjunctiva densely spinulose.

Segment VIII. Tergum separated by a spacious discal area into two lateral plates whose caudal extremities flare, adhering to the margin to fuse as a narrow marginal plate, cephalad the plates broaden slightly; discal area divided by a median, interrupted thickening of the chitin; marginals diverse, irregular. Sternum composed of two elongate sclerites pointed at both extremities, attaining but half the length of the segment; setæ few, distributed irregularly; conjunctiva spinulose.

Segment IX. Suranal plate scoop-shaped to hemispherical; setæ wide apart, exceeding the width of the club, setulæ few, long; subanal plate conical, pubescent; setæ long, fine, approximate, setulæ sparsely distributed over the surface; cerci slender, densely pubescent; club subcylindrical; petiole slender, longer than the club; apicals long and fine, setulæ long, few, bristlelike; sense organs consist of two tubercles.

\section{Hylemia lipsia Walker.}

Segments and intersegments of equal length, sclerites glabrous. Intersegments smooth, hyaline, transparent.

Segment VI. Tergum thinly chitinized extending from side to side as a broad plate, cephalic margin indeterminate, incised; discal area vestigial; accessory pieces large, setæ thickly distributed; spiracles approximate, oblique, cephalad of the accessory pieces. Sternum obconic, truncate caudad, pointed cephalad, attaining three quarters the length of the segment; marginals diverse, regular, distributed along the caudal margin; conjunctiva smooth, hyaline.

Segment VII. Tergum composed of two lateral chitinous plates whose extremities flare caudad to partially coincide with the margin, cephalad the plates taper, not reaching the margin; discal area spacious, hyaline; accessory pieces large, bearing numerous setæ; marginals numerous, diverse, irregular. Sternum reduced to two short chitinous strips on either side of the mid-dorsal line adjacent to the caudal margin; marginals diverse, irregular, closely distributed; conjunctiva membranous, hyaline, occupying the whole ventral area.

Segment VIII. Tergum divided into two chitinous plates, dorsocentral, that flare and fuse together along the caudal margin, cephalad the plates taper and fail to reach the margin; discal area hyaline, transparent; marginals diverse, irregular. Sternum reduced to two small ovoid sclerites adjacent to the caudal margin, pointed at both extremities; setæ few; conjunctiva smooth, hyaline.

Segment IX. Suranal plate triangular; setæ the width of the club apart; subanal plate conical, glabrous; setæ regular; setulæ few; cerci short, knobbed, sessile; apicals single, setulæ confined to the distal half. 


\section{Hylemyia setiventris Stein.}

Segments and intersegments of equal length, sclerites glabrous except the subanal plate which is pubescent. Intersegments heavily spinulose except the fourth, which is smooth throughout.

Segment VI. Tergum divided by a lightly chitinized discal area into two heavily chitinized lateral plates whose caudal and cephalic extremities expand dorsad along their respective segmental margins, almost fusing across the mid-dorsal line, the plates blend imperceptibly with the discal area; accessory pieces present; marginals few, even, regular; spiracles wide apart, oblique, posterior spiracles cephalad of the accessory pieces and twice the diameter of the anterior spiracles, the latter small, situated in the conjunctiva. Sternum elongate, extending the length of the segment, tapering cephalad; marginals divided into two lateral groups; conjunctiva densely spinulose.

Segment VII. Tergum separated by a lightly chitinized discal area into two broad lateral plates that tend to approximate cephalad, the caudal extremities expanded dorsad aloff the margin; accessory pieces present; marginals equal, regular. Sternum lanceolate, extending for the length of the segment, tapering at both ends; marginals divided into two lateral groups; conjunctiva spinulose except for a cephalic area bordering the segmental margin.

Segment VIII. Tergum composed of two lateral rodlike chitinous plates that partially enclose a spacious, lightly chitinized discal area, the plates approximate at the cephalic margin, caudad the extremities adhere to the margin as chitinous strips, nearly fusing across the middorsal line; marginals diverse, regular, terminating at both sides in a group of setæ. Sternum reduced to two, broadly ovoid sclerites adjacent to the caudal margin; setæ distributed over the entire surface; conjunctiva smooth.

Segment IX. Suranal plate scoop-shaped to hemispherical, armed with six or seven stout black spines; subanal plate spade-shaped, pubescent, setæ and setulæ long, fine, hairlike, the latter distributed densely over the surface; cerci smooth, knobbed, sessile, armed with numerous stout upcurving spines on the dorsal surface, on the ventral surface clothed with fine, hairlike setæ; sense organs consist of two tubercles, situated laterad, from which emerge two bristlelike papillæ.

\section{Hylemyia strigosa var. nigrimana Fabricius. $\dagger$}

Ovipositor short, compact, equalling the fifth abdominal segment in length. Segments much longer than the intersegments, breadth three times the length. Intersegments spinulose except the fourth which is smooth on the ventral surface.

Segment VI. Tergum smooth, composed of a broad, bandlike discal area, lightly chitinized, separating two small quadrangular plates which are confined to the lateral margins of the segment; accessory pieces absent; marginals few, regular; spiracles large, exceeding the breadth of the sternum apart, posterior spiracles mesad of the anterior, both

\footnotetext{
$\dagger$ European specimen.
} 
situated along the ventral margin. Sternum spinulose, lanceolate, attaining the length of the segment; marginals separated into two lateral groups; conjunctiva spinulose.

Segment VII. Similar in structure to segment VI, the sternum spinulose, expanding into a broader sclerite caudad; marginals wide apart; conjunctiva spinulose.

Segment VIII. Tergum spinulose, divided by the median discal area into two broad quadrangular lateral plates; marginals diverse, irregular. Sternum spinulose, consisting of two elongate sclerites, attaining the length of the segment, tapering at both extremities; setæ few, usually two; conjunctiva smooth.

Segment IX. Suranal plate pubescent, scoop-shaped; setæ long and stout, sttulæ numerous, bristlelike; subanal plate spinulose, broadly spade-shaped; setæ, three pairs on the apical third, setulæ diverse, numerous; cerci pubescent, short petiole, knobbed; apicals stout, setulæ diverse, long and stout, distributed over the distal region; sense organs consist of two spined tubercles.

\section{Hylemyia variata Fallen.}

Segments longer than the intersegments, breadth twice the length. Intersegments spinulose except the fourth which is smooth on the ventral surface. Spinules arranged in no regular striations.

Segment VI. Tergum spinulose, divided by a thinly chitinized median strip into two quadrangular plates which encase the sides of the segment, dorsal and ventral borders ragged; accessory pieces absent; marginals equal, even, regular; spiracles barely the breadth of the sternum apart, oblique, posterior spiracles situated cephalad of the caudal margin. Sternum spinulose, attaining the length of the segment, broadly expanding caudad, tapering to a blunt point cephalad; marginals widely separated into two lateral groups; conjunctiva densely spinulose.

Segment VII. Similar in structure and character to segment VI. The tergum divided by a more pronounced median discal area into two lateral quadrangular plates, the latter are not so extensive as in segment VI. Sternum tapering more decidedly to a point, scarcely attaining the caudal margin.

Segment VIII. Tergum divided by a broadly expanding discal area into two broad, lateral, heavily chitinized plates, the latter expanded caudad, adhering to the margin and almost fusing across the middorsal line; marginals few, equal, regular; the region along the caudal margin and projecting for some distance onto the discal area densely spinulose. Sternum glabrous, composed of two small elongate to oval sclerites, adjacent to the caudal margin; setæ distributed irregularly; conjunctiva smooth.

Segment IX. Suranal plate pubescent, hemispherical, setæ approximate long; subanal plate spinulose, spade-shaped, setæ and setulæ nearly equal, few and sparsely distributed over the surface; cerci pubescent, knobbed, short petiole; apicals long and stout, setulæ distributed over the club; sense organs apical, consisting of two spined tubercles. 


\section{Genus Pegomyia Desvoidy.}

Pegomyia affinis Stein.

Segments slightly longer than the intersegments except segment and intersegment eight which are foreshortened, sclerites glabrous. Intersegments smooth, hyaline, transparent.

Segment VI. Tergum thinly chitinized, covering the entire dorsal region, margins indeterminate; accessory pieces present; marginals diverse, slightly irregular; spiracles approximate, oblique, cephalad of the accessory pieces. Sternum lanceolate, extending for the entire length of the segment, expanding slightly caudad; marginals distributed laterad; conjunctiva smooth, hyaline.

Segment VII. Tergum divided by a hyaline discal area into two lateral pieces which extend from margin to margin as more or less uniform plates; accessory pieces large, distinct; marginals diverse, irregular. Sternum spatulate, the caudal extremity flaring, truncate; marginals approximate, distributed in a semi-circle around the margin; conjunctiva smooth, hyaline.

Segment VIII. Tergum reduced in size to form a lightly chitinized, archlike plate, the margins indeterminate, blending imperceptibly with the discal area. Sternum consists of two small elongate sclerites onehalf the length of the segment; setæ few, distributed on the caudal third; conjunctiva smooth.

Segment IX. Suranal plate triangular to conical; setæ short, approximate, less than the width of the club apart; subanal plate broadly spade-shaped; setæ irregular, approximate; setulæ absent; cerci smooth, small, knobbed, sessile; apicals short, stout; setulæ distributed on the distal portion of the club.

\section{Pegomyia calpytrata Zetterstedt.}

Ovipositor short, compact, slightly longer than the fifth abdominal segment, spinulose throughout, segments longer than the intersegments, breadth twice the length. Intersegments reduced to narrow transverse membranes.

Segment VI. Tergum completely chitinized encasing the entire tergal region, posterior angles produced ventrad to embrace the sides of the segment; marginals few, one or two; accessory pieces present, distinct; spiracles in the same plane, not oblique, wide apart, posterior spiracles situated on the caudal margin of segment. Sternum consists of an oblong sclerite, truncate at both extremities, extending the entire length of the segment, the posterior region densely covered with black, short spines, which continue sparsely along the lateral borders; conjunctiva spinulose.

Segment VII. Tergum similar in structure to segment VI; marginals diverse, regular, confined to the caudal margin of the posterior angles of the tergum; accessory pieces absent. Sternum broadly conical, the apex reaching the cephalic margin, posterior half densely clothed with black, short spines, hooked at the tip; conjunctiva spinulose. 
Segment VIII. Tergum reduced to two subtriangular tergites whose posterior angles are produced ventrad and dorsad, coinciding with the caudal margin, cephalad the apices reach the cephalic margin; discal area membranous, widely separating the tergites and occupying the entire dorsal region; marginals diverse, irregular. Sternum reduced to two small triangular sclerites adjoining the cephalic margin; setæ short, fine; conjunctiva spinulose.

Segment IX. Suranal plate broad, scoop-shaped, apex rounded; setæ wide apart, equal to the breadth of the club, setulæ numerous, strong; subanal plate broadly spade-shaped; setæ stout, distributed apically and at the basal angles; setulæ short, surrounding a spinulose discal area; cerci spinulose, ovoid, sessile; apicals single; setulæ few, confined to the distal region of the club; sensory organs, small, apical.

\section{Pegomyia hyoscyami Panzer.}

Ovipositor short, compressed, slightly longer than the fifth abdominal segment, spinulose except for the cephalic margin of the sternites; the latter longer than the intersegments, breadth twice length. Intersegments reduced to narrow transverse membranes.

Segments VI. Tergal region occupied by a spacious discal area, extending from side to side, margin to margin; bounded laterally by angular chitinous plates that project ventrad; accessory pieces absent; marginals diverse, irregular; spiracles wide apart, in the same plane, posterior spiracles situated caudad of the margin, in the membrane of the second intersegment. Sternum consists of a broad plate, similar to that of the fifth abdominal segment, posterior angles rounded, anterior angles square, the entire surface except along the cephalic margin covered with diverse setæ, cephalic margin glabrous; conjunctiva reduced to narrow articulating membranes between the sternum and tergum.

Segment VII. Tergum similar to segment VI in appearance, the tergites confined to the caudo-ventral regions of the dorsum, tapering cephalad and dorsad, the ventral margins anastamose with the borders of the sternum, appearing to form a continuous sclerite with the sternum, the dorsal margin glabrous, the remaining surface sparsely covered with diverse setæ. Sternum cordate, humped anteriorly, occupying nearly the whole sternal region, lateral borders anastamose with the ventral margin of the tergites, cephalic margin glabrous, the remaining surface covered with setæ; conjunctiva reduced to the cephalic margin, and is confluent with the tergal membrane.

Segment VIII. Tergum composed of a transverse chitinous plate, completely encasing the tergal region, spinulose except for a hemispherical area along the cephalic margin; marginals irregular, distributed along the caudal margin and about the ventral region. Sternum composed of three chitinous sclerites; two lateral hemispherical sclerites, approximating toward the caudal margin, gradually diverging cephalad; into the angular space thus formed fits the triangular apex of the median anterior sclerite, the latter continues cephalad as a narrow plate, surpassing the cephalic margin and dissecting the third intersegment into two lateral regions; the sclerites are spinulose except for the dorsal 
area of each lateral plate and the anterior portion of the median sclerite, included amongst the spinules are a few short setæ; conjunctiva reduced to narrow articulating membranes between the sternites and the tergites.

Segment IX. Suranal plate broad, transverse; setæ long, wide apart; setulæ scattered; subanal plate spade-shaped; setæ distributed apically, setulæ distributed over the entire surface; cerci spinulose, knobbed, sessile; apicals strong; setulæ short, fine, distributed on the distal region of the club.

\section{Pegomyia trilineata Stein.}

Segments longer than the intersegments. Sclerites glabrous except the sternum and accessory pieces of the sixth segment which are partly spinulose, and the subanal plate which is wholly spinulose. Intersegments smooth, hyaline.

Segment VI. Tergum lightly chitinized, with thicker areas along the caudal, cephalic and lateral margins. These plates blend imperceptibly into a large semi-translucent discal area. Marginals short, diverse, more or less regular; accessory pieces present, partly spinulose; spiracles oblique, adjoining the accessory pieces. Sternum spatulate, cephalic half but faintly chitinized, at the tip of which is a pair of sensory organs, caudal half spinulose, hexagonal in outline; marginals in two lateral groups; conjuctiva spinulose on the caudal half, hyaline and smooth cephalad.

Segment VII. Tergum divided into two lateral plates that fuse across the caudal margin; discal area large, semi-translucent, confining the plates to the lateral margins of the segment; marginals as in segment VI; accessory pieces present. Sternum spatulate, glabrous, with but a few if any spinules; marginals and sense organs as in segment VI; conjunctiva smooth, hyaline, with a very few spinules along the caudal margin.

Segment VIII. Tergum completely and heavily chitinized, encasing the dorsal region, cephalic margin emarginate, a short chitinous tooth at the caudal end of the middorsal line; marginals short, diverse, irregular. Sternum composed of two strongly chitinized, elongate plates reaching three-quarters the length of the segment; setæ short, confined to the caudal third of the sternites; conjunctiva, smooth, semi-opaque.

Segment IX. Suranal plate scoop-shaped, setæ short, approximate; subanal plate spade-shaped, setæ normal, setulæ long around the caudal margin, short and thornlike on the plate; cerci glabrous, subcylindrical, petiolate, apicals one per club, setulæ short, distributed on the club and petiole, at the apex of the former are two strikingly recurrent setulæ.

\section{Pegomyia trivittata Stein.}

Segments longer than the intersegments. Sclerites glabrous except the sternum of the seventh segment which bears numerous stout, short spines. Intersegments heterogeneous; the first smooth on the dorsal surface, on the ventral surface spinulose throughout the cephalic half, smooth caudad; second intersegment spinulose, densely so along 
the cephalic margin of the dorsal surface, very lightly for the remaining region, on the ventral surface spinulose along the cephalic margin and for a short distance caudad along the midventral line, the remaining region smooth. Intersegment three spinulose on both surfaces except for a posterior margin of smooth hyaline membrane. Intersegment four smooth throughout.

Segment VI. Tergum thinly chitinized, completely encasing the dorsal region, cephalic margin ragged; accessory pieces present clothed, with numerous setæ; marginals diverse, distributed closely together and irregularly; spiracles approximate, oblique, cephalad of the accessory pieces. Sternum reduced to two spherical chitinous areas adjacent to the caudal margin; marginals diverse scattered over the entire surface; conjunctiva adjoining the sternites densely spinulose, remainder smooth.

Segment VII. Tergum similar in structure to segment VI except that the chitin along the mid-dorsal line is much thinner, dividing the tergum into lateral plates; accessory pieces present; the marginal region and the accessory pieces possess numerous short, stout, spines amongst which are scattered a few longer bristles. Sternum reduced to two ovoid chitinous pieces adjacent to the caudal margin, which are covered throughout their entire area with numerous short, stout, spines; marginals few, usually two; conjunctiva densely spinulose between the tergum and sternites and for a short distance cephalad, remaining region smooth.

Segment VIII. Tergum divided by a spacious hyaline discal area into two lateral plates which taper gradually to the cephalic margin; marginals surplanted by a row of stiff, short, spines. Sternum composed of two elongate sclerites attaining one-half the length of the segment, the apical third armed with stout, short spinules; conjunctiva spinulose along the caudal margin, smooth for the remaining region.

Segment IX. Suranal plate subtriangular, setæ approximate; subanal plate broadly spade-shaped, setæ regular, setulæ sparsely distributed over the surface; cerci, small, knobbed, smooth, sessile; apicals short and stout, setulæ confined to the club; sense organs tubercular, with sharp apical spines.

\section{Pegomyia unicolor Stein.}

Segments longer than the intersegments, sclerites glabrous on the dorsal surface, spinulose on the ventral, lightly chitinized throughout, armed with bunches of stout spines. Intersegments smooth, hyaline.

Segment VI. Tergum lightly chitinized, hyaline, slightly thickened around the caudal margin; accessory pieces present, armed with numerous stiff bristles; marginals stout, equal, regular, usually eight in number, distributed dorsad; spiracles the width of the sternum apart, oblique, orifices surrounded by a broad brim or margin, situated in the conjunctival membrane. Sternum short, conical, attaining one-third the length of the segment, sparsely covered with spinules; marginals approximate, in a semi-circle around the margin; conjunctiva smooth, hyaline, the caudal border with a few stout setæ. 
Segment VII. Tergum lightly chitinized, the sides and the caudal margin slightly thickened into two faintly perceptible lateral plates which are separated by a hyaline, transparent discal area; accessory pieces present, armed with stiff, stout bristles. Sternum densely spinulose, reduced to a short transverse sclerite adjacent to the caudal margin; marginals scattered; conjunctiva smooth, constricted at the caudal limits by the accessory pieces.

Segment VIII. Tergum composed of two lateral plates, broadly separated throughout by a spaceous hyaline discal area, the caudal region characterized by a tuft of dense short hair, the caudal margins of the tergites are armed with a few stout stiff bristles. Sternum densely spinulose, composed of two somewhat raised sclerites adjacent to the caudal margin and nearly fusing across the mid ventral line, the outer halves of each sternite bear numerous stiff setæ; conjunctiva smooth for the greater part, sparsely spinulose along the caudal margin.

Segment IX. Suranal plate scoop-shaped; setæ approximate, short, stout; setulæ few; subanal plate spinulose, conical; setulæ few; subanal plate spinulose, conical; setæ apical; setulæ long, spinelike, sparsely distributed over the distal half; cerci small, subcylindrical; apicals short and stout; setulæ few, stout, confined to the club; sensory organs tubercular, spined, scattered over the club.

Pegomyia winthemi Meigen.

Segments slightly longer than the intersegments, sclerites glabrous except the sternum of segment eight which is pubescent and the subanal plate which possesses a few scattered spinules. Intersegment one spinulose throughout; the second spinulose along the cephalic region and for a short distance caudad along the mid dorsal and mid-ventral lines, the remaining surfaces smooth; intersegment three smooth on the dorsal surface with a narrow strip of spinules along the cephalic margin, densely spinulose for three-quarters the length of the ventral surface, the caudal margin smooth, hyaline; fourth intersegment spinulose throughout.

Segment VI. Tergum completely but thinly chitinized, encasing the entire tergal region; accessory pieces absent; marginals diverse regular; spiracles situated close together, oblique, less than the width of the sternum apart. Sternum lanceolate, attaining the length of the segment, apex rounded caudad; marginals approximate, divided into two groups; conjunctiva spinulose for the caudal third, smooth for the remainder of the surface.

Segment VII. Tergum composed of two broad lateral plates whose caudal extremities fuse across the mid-dorsal line, cephalad the chitinization is well maintained; discal area hyaline; marginals diverse, irregular. Sternum reduced to a short lanceolate sclerite attaining onehalf the length of the segment, pointed caudad, tapering cephalad; marginals preapical, in two groups; conjunctiva spinulose for the caudal third, smooth for the remaining surface. 
Segment VIII. Tergum composed of two lateral plates whose caudal extremities develop dorsad to fuse across the mid-dorsal line, cephalad the plates taper and tend to approximate; discal area hyaline; marginals equal, regular. Sternum composed of two ovoid sclerites with the apices prolonged to a point, attaining one-half the length of the segment; setæ few, one or two, the surface densely pubescent; conjunctiva smooth, hyaline, fringed with pubescense at the caudal margin.

Segment IX. Suranal plate scoop-shaped; setæ wide apart, exceeding the width of the club; setulæ few; subanal plate sparsely spinulose, spade-shaped to conical; setæ regular, strong, bristlelike, setulæ short, scattered over the entire surface; cerci glabrous, knobbed, shortly petiolate; apicals and setulæ similar in size and length, stout, bristlelike, distributed over the club and petiole; sense organs consist of three spined tubercles situated laterad.

\section{KEY.* \\ (Exclusive of Pegomyia Desv.)}

A. Cerci pubescent or spinulose.

B. Conjunctiva of segment VII smooth

C. Suranal plate pubescent, cerci pubescent, intersegment 3 spinulose.

D. Sternites of segment VIII spinulose, attaining almost to the cephalic margin.................. strigosa var. nigrimana Fabr.

DD. Sternites of segment VIII glabrous, confined to caudal region. variata Fall.

CC. Suranal plate glabrous, cerci slightly spinulose, intersegment 3 spinulose on the ventral surface, smooth on the dorsal region. .

dissecta Meig.

BB. Conjunctiva of segment VIII spinulose.

C. Segment VIII with sternites spinulose, tergum partly spinulose

fugax Meig. substriata Stein.

CC. Segment VIII with sternites and tergites glabrous.....juvenilis Stein.

AA. Cerci glabrous, suranal plate glabrous.

B. Cerci armed with upcurving stout spines.

C. Sternites of segment VIII armed with upright, stout spines, suranal plate with 4 large hooks, cerci clothed with but few setæ,

candens Zett.

CC. Sternites of segment VIII clothed with setæ, suranal plate armed with numerous short hooks, cerci with conspicuous apical tufts

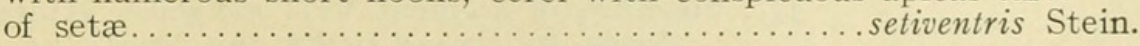

BB. Cerci clothed with setæ.

C. Subanal plate glabrous, subtriangular.

D. Subanal plate setulose, sternites of segment VIII attaining the length of the segment, conjunctiva spinulose........rubivora Coq.

DD. Subanal plate with but one or two setulæ at most, sternites of segment VIII small, adjacent to the caudal margin, conjunctiva smooth, hyaline.

lipsia W1k.

* For the sake of feasibility the characters have been restricted to the distal end of the ovipositor, with the exception of one couplet. 
CC. Subanal plate spinulose, spade-shaped.

D. Segment VIII with marginals scattered, discal area spinulose, sternites thin, chitinous strips attaining the cephalic margin,

DD. Segment VIII with marginals bordering the caudal margin, muscaria Meig. discal area smooth, sternites flaring caudad.

E. Sternites of segment VIII equal in length to the tergites.

F. Suranal plate scoop-shaped................... parva R. D.

FF. Suranal plate hemispherical.................. cinerella F11.

EE. Sternites of segment VIII shorter than the tergites, failing to attain the cephalic margin.

F. Third intersegment smooth, sense organs 4 .

G. Intersegment 4 heavily chitinized, fused to the margin of segment VIII, membranes covered with chitinous granulations............................. grisella Rond.

GG. Intersegment 4 hyaline, transparent, membranes thin, delicate............................... longula F11.

FF. Third intersegment smooth on the dorsal surface, spinulose on the ventral surface.

G. Setæ of the suranal plate approximate, closer together than the width of club, accessory pieces absent on segments VI and VII.................flavipennis Stein.

GG. Setæ of the suranal plate the width of the club apart, accessory pieces present on segments VI and VII,

coarctata F11.

FFF. Third intersegment partly smooth, partly spinulose on the dorsal surface, spinulose on the ventral surface...aemene W1k. alcathoe W1k.

FFFF. Third intersegment spinulose. flavicans Stein.

G. Spinules broad, imbricated, scale-like.......caerulescens Strobl.

GG. Spinules fine, recurrent, hooklike.

H. Conjunctiva of segment VIII spinulose........ laevis Stein.

HH. Conjunctiva of segment VIII smooth.

I. Tergites of segment VIII undulating.

J. Cerci short, compact, petiole short, intersegment 4 smooth, tergites slightly undulating... antiqua Meig.

JJ. Cerci elongate, subcylindrical, petiole slender, intersegment 4 spinulose on the dorsal surface, tergites markedly undulating............. brassice Bouché.

II. Tergites of segment VIII straight, approximating.

J. Sternites of segment VIII short, ventral surface of intersegment 4 smooth...............nuda Strob1.

JJ. Sternites of segment VIII elongate, attaining twothirds to three-fourths the length of segment, ventral surface of intersegment 4 spinulose, 


\section{REFERENCES.}

1782. Degeer, K. Abhandlungen zur Geschichte der Insekten. VI : 11. 37. Taf. 4 , fig. 8 .

1826. Meigen, J. W. Systematische Beschreibung der bekannten Europaischen

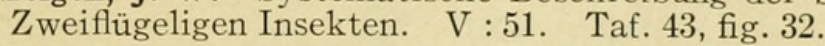

1828. Kirby W. and Spence, W. An Introduction to Entomology. III : 706. IV : 163. pl. 16, Figs. 2, 3.

1832. Burmeister, H. Handbuch der Entomologie. I : 118, 119. Taf. 12, fig. 33.

1844. Dufour, L. Anatomie Generale des Diptères. Annales des Sciences Naturelles. ser 3. (Zool.) I : 257-264.

1853. Lacaze-Duthiers. De 1'Armature Genitale Femelle des Insectes Diptères. Annales des Sciences Naturelles. ser. 3. (Zool.) XIX:69-88. pl. 4.

1895. Heymons, R. Die Segmentirung des Insecten Korpers. 26-37. Taf. 1.

Lowne, T. The Anatomy, Physiology, Morphology and Development of the Blow Fly (Calliphora erythrocephala). II : 745-747. Figs.

1897. Bruel, L. Anatomie und Entwicklungsgeschichte der Geschlechtausfuhrwege von Calliphora erythrocephala. P. 54-56.

1902. Berlese, A. L'accoppiamento della Musca domestica. Rivista di Patologia Vegetale. (1901): IX 350-351. Figs.

1906. Wesche, W. The Genitalia of both the Sexes in Diptera, and their Relation to the Armature of the Mouth. The Transactions of the Linnean Society of London. ser. 2. (Zool.) IX : 339-386. pl. 23-30.

1914. Hewitt, C. G. The House Fly. Cambridge University Press, p. 50-52. Figs.

Stein, P. Versuch, die Gattungen und Arten unserer Anthomyiden nur nach dem weiblichen Geschlecht zur bestimmen. Archiv für Naturgeschichte. 1913: VIII 4-55. 


\section{EXPLANATION OF PLATES.*}

Plate XX.

Fig. 1. Chortophila dissecta Meig.

Fig. 2. Chortophila longula Fall.

Fig. 3. Chortophila candens Zett.

Fig. 4. Chortophila cilicrura Rond.

\section{Plate XXI.}

Fig. 5. Chortophila antiqua Meig.

Fig. 6. Chortophila brassicæ Bouche.

Fig. 7. Chor tophila rubivora Coq.

Fig. 8. Chortophila nuda Strobl.

\section{Plate XXII.}

Fig، 9. Chortophila parva R-D.

Fig. 10. Chortophila cinerella Fall.

Fig. 11. Chortophila caerulescens Strob1.

Fig. 12. Chortophila muscaria Meig.

\section{Plate XXIII.}

Fig. 13. Chortophila grisella Rond.

Fig. 14. Chortophila laevis Stein.

Fig. 15. Chortophila fugax Meig.

Fig. 16. Hylemyia lipsia W1k.

\section{Plate XXIV.}

Fig. 17. Hylemyia variata Fall.

Fig. 18. Hylemyia coarctata Fall.

Fig. 19. Hylemyia juvenilis Stein.

Fig. 20. Hylemyia setiventris Stein.

\section{Plate XXV.}

Fig. 21. Hylemyia flavipennis Fall.

Fig. 22. Hylemyia aemene W1k.

Fig. 23. Pegomyia trilineata Stein.

Fig. 24. Pegomyia winthemi Meig.

\section{Plate XXVI.}

Fig. 25. Pegomyia affinis Stein.

Fig. 26. Pegomyia unicolor Stein.

Fig. 27. Pegomyia calyptrata Zett.

Fig. 28. Pegomyia trivittata Stein.

\section{Plate XXVII.}

Fig. 29. Pegomyia hyoscyami Panz.

Fig. 30. Hylemyia strigosa var. nigrimana Fabr.

* Each Figure is represented by two drawings, of which the left hand one denotes the dorsal aspect, the right hand one the ventral aspect of the ovipositor. 


\section{$2 \mathrm{BHL}$ Biodiversity Heritage Library}

Huckett, H C. 1921. "On the Morphology of the Ovipositor of Certain Anthomyian Genera." Annals of the Entomological Society of America 14, 290-320. https://doi.org/10.1093/aesa/14.4.290.

View This Item Online: https://www.biodiversitylibrary.org/item/43628

DOI: https://doi.org/10.1093/aesa/14.4.290

Permalink: https://www.biodiversitylibrary.org/partpdf/193546

\section{Holding Institution}

Smithsonian Libraries

\section{Sponsored by}

Smithsonian

\section{Copyright \& Reuse}

Copyright Status: NOT_IN_COPYRIGHT

This document was created from content at the Biodiversity Heritage Library, the world's largest open access digital library for biodiversity literature and archives. Visit BHL at https://www.biodiversitylibrary.org. 